\title{
Measurements of dust deposition velocity in a wind-tunnel experiment
}

\author{
J. Zhang ${ }^{1,2}$, Y. Shao ${ }^{2}$, and N. Huang ${ }^{1}$ \\ ${ }^{1}$ Key Laboratory of Mechanics on Disaster and Environment in Western China of the Ministry of Education of China, \\ Lanzhou University, 730000 Lanzhou, China \\ ${ }^{2}$ The Institute for Geophysics and Meteorology, University of Cologne, 50973 Cologne, Germany
}

Correspondence to: J. Zhang (zhang-j@1zu.edu.cn)

Received: 28 November 2013 - Published in Atmos. Chem. Phys. Discuss.: 8 April 2014

Revised: 2 July 2014 - Accepted: 18 July 2014 - Published: 1 September 2014

\begin{abstract}
In this study, we present the results of a windtunnel experiment on dust deposition. A new method is proposed to derive dust deposition velocity from PDA (particle dynamics analysis) particle-velocity and particle-size measurements. This method has the advantage that the motions of individual dust particles are directly observed and all relevant data for computing dust deposition velocity is collected using a single instrument, and thus the measurement uncertainties are reduced. The method is used in the wind-tunnel experiment to measure dust deposition velocities for different particle sizes, wind speeds and surface conditions. For sticky-smooth wood and water surfaces, the observed dust deposition velocities are compared with the predictions using a dust deposition scheme, and the entire data set is compared with the data found in the literature. From the wind-tunnel experiments, a relatively reliable data set of dust deposition velocities is obtained, which is valuable for the development and validation of dust deposition schemes.
\end{abstract}

\section{Introduction}

In the past few decades, the dust research community has been struggling to develop dust emission and deposition schemes for large scale dust models. As far as dust emission is concerned, several wind-tunnel and field observations (e.g. Gillette, 1977; Shao et al., 1993; Ishizuka et al., 2008) have been carried out, which serve as the basis for the conceptualization of dust emission schemes (Shao, 2001, 2004; Marticorina and Bergamatti, 1995; Alfaro and Gomes, 2001). The understanding of dust deposition is at least as poor as that of dust emission (Goossens and Offer, 2000). The samplers used for dust-deposition measurements in field experiments have been found to be quite inefficient (Sow et al., 2006). The large uncertainties in dust-deposition estimates in regional and global dust models have been documented by Uno et al. (2006) and Textor et al. (2006, 2007). Our preliminary tests of existing dust deposition schemes show that the scheme estimates can easily differ by an order of magnitude, and it is often unclear how the scheme parameters should be specified in regional and global dust models.

We must come to terms with several problems in dustdeposition parameterizations, but the most outstanding is the serious lack of high-quality and cohesive data sets for testing dust-deposition theories and schemes. Field observations on dust deposition over time intervals of days and weeks have been made using direct or indirect techniques (e.g. Gao et al., 1997; Liu et al., 2004). Such observations are valuable in determining the order of magnitude of dust deposition for given areas, but do not provide sufficient details for the conceptualization and derivation of dust-deposition theories. Chamberlain (1967) conducted a wind-tunnel experiment on the deposition of particles of various sizes over a surface of artificial sticky grass. His data have proved to be very useful for the verification of dust-deposition schemes. However, natural surfaces are very different from a sticky grass surface in physical and aerodynamic characteristics. Only very few surface types have been investigated in wind-tunnel studies so far, and to our knowledge no equivalent field experiments have ever been carried out.

Dust deposition is mostly parameterized through deposition velocity, $w_{\mathrm{d}}$, and in most dust-deposition experimental 


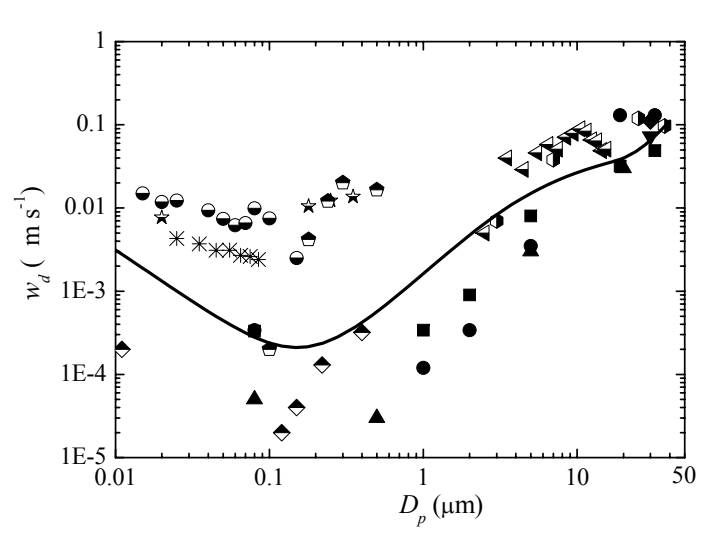

\begin{tabular}{lll} 
Wind Tunnel: & Surface & $\boldsymbol{u}_{*}\left(\mathbf{m ~ s}^{-1}\right)$ \\
- Chamberlain (1967) & Grass & 0.7 \\
- Chamberlain (1967) & Sticky grass & 0.7 \\
- Clough (1973) & Filter paper & 0.24 \\
- Clough (1975) & Dry tray & $0.37-0.87$ \\
& Wet tray & $0.37-0.87$ \\
Field: & & \\
4 Gallagher et al. (1988) & Moorland & 0.57 \\
- Nemitz et al. (2002) & Moorland & $0.1-0.7$ \\
Beswick et al. (1991) & Spruce & $0.37-0.7$ \\
$\star$ Bleyl (2001) & Spruce & $/$ \\
- Groenholm et al. (2007) & Pine & $0.08-1.28$ \\
Gallagher et al. (1997) & Fir & $0.15-0.75$ \\
* Pryor et al. (2007) & Forest & $/$ \\
\hline & & 0.25
\end{tabular}

Figure 1. Some existing measurements of deposition velocities against particle size for different surfaces.

studies, measurements of dust flux and/or concentration are made for the estimation of $w_{\mathrm{d}}$ (Sehmel, 1971; Wesley et al., 1983; Gallagher et al., 1997; Ould-Data, 2002; Pryor et al., 2008). Various techniques and devices have been used (Seinfeld and Pandis, 2006) and measurements made under different conditions. As a consequence, the comparability between the data sets has been poor (Wesely et al., 1985; Hicks et al., 1989; Goossens and Rajot, 2008). As shown in Fig. 1, a large scatter over orders of magnitude among the measurements published in the literature exists. The scatter may be caused by the uncertainty in measuring techniques and the differences in experimental conditions. The lack of knowledge in measurement precision and the unrecorded information of experimental conditions undermine the value of the measurements for the validation of models. A considerable discrepancy between the measurements and the model estimates is also apparent, due to reasons which are yet to be fully explained.

In this paper, we propose a new method for measuring dust deposition velocity using a single device: a particle dynamics analysis (PDA). This technique has the advantage of observing the motion of individual particles and avoids uncertainties arising from using a combination of devices. Windtunnel experiments are carried out by using the PDA to measure dust deposition velocities for various surfaces, ranging from a sticky-smooth wood surface (wood surface hereafter) to a rough vegetation surface, and a reliable data set is obtained. The measurements are then used to test the Slinn and Slinn (1980, SS80 hereafter) scheme for smooth (wood and water) surfaces. The advantages of our technique are demonstrated and the possible improvements required in the SS80 scheme are identified. The dust deposition velocities measured in our experiments are compared with those of several other experiments published in the literature after correction of all data to $1 \mathrm{~m}$ above the zero-plane displacement height.

\section{Particle dynamics analysis (PDA) and wind-tunnel ex- periment}

PDA is an extension of LDA (laser Doppler anemometry), which can measure both the velocity and size of a particle passing through the measuring point. Particle velocity is measured by using the laser Doppler effect and particle size according to the phase shift between two signals of the scattered light detected by different detectors (Dantec Dynamics $\mathrm{A} / \mathrm{S}, 2006)$.

Figure 2 illustrates the functioning principle of PDA. A laser beam emitted from the generator is split into two coherent beams. These beams intersect to form a measuring point with an elliptical volume and the interference produces parallel bright and dark planes, known as fringes. The distance between the fringes depends on the laser wavelength and the angle between the incident beams (upper right corner of Fig. 2). When a particle moves across the fringes, a current pulse (right hand of Fig. 2) will be generated by the photodetector because of the changing intensity of the light scattered by the particle, which alternates between the bright and dark fringes. The time interval between the peaks of pulses can be obtained and the particle displacement (in the direction perpendicular to the fringes) is the spacing of adjacent fringes. The velocity component orthogonal to the fringes is accordingly calculated. This is the so called "fringes model" of PDA. Also, an aperture plate as shown in the lower right corner of Fig. 2 is fixed in the receiver probe to create several light detectors, and the phase shift between the Doppler signals from the different detectors can be obtained to deduce the size of the passing particle.

The structure of the Lanzhou University (LZU) wind tunnel is shown in Fig. 3. It is a blow-down wind tunnel of $55 \mathrm{~m}$ length, including a fan, a rectification section, a working section and a diffuser. High-speed and turbulent wind can be generated by the fan of $75 \mathrm{~kW}$. The turbulent air flows into the rectification section where the flow speed slows down 


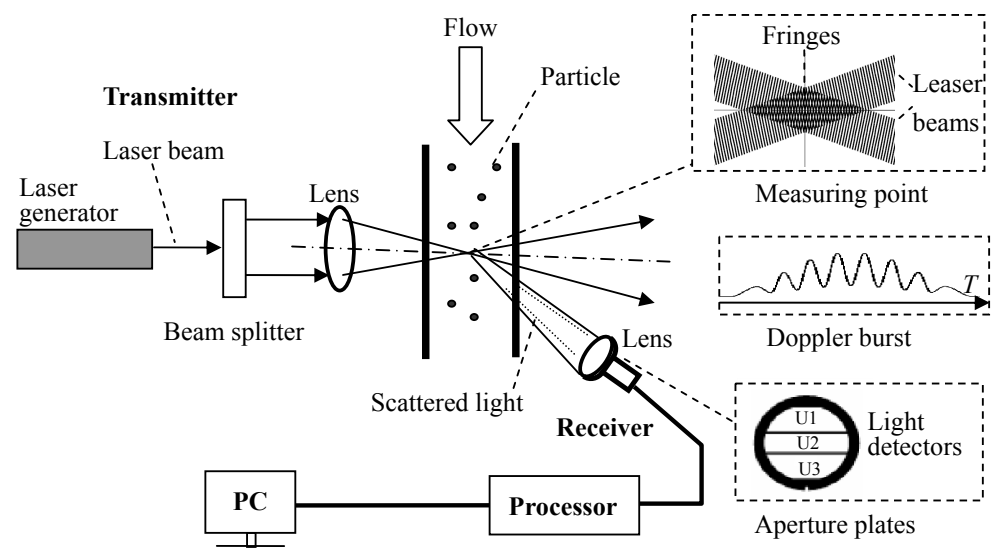

Figure 2. Basic structure of PDA. The velocities and sizes of particles passing through the measuring point are obtained by analyzing the light scattered by the particles.

because of the bigger cross-section. Turbulent eddies in the original flow generated by the fan are destructed by a combination of honeycomb and damping screens (rectangular grids) deployed in this part. After passing the rectification section, the air flow becomes uniform. The rectified air flow is accelerated in the working section which has a smaller but uniform cross-section of $1.3 \mathrm{~m} \times 1.45 \mathrm{~m}(w \times h)$. The length of the working section is about $22 \mathrm{~m}$. Some spires or roughness elements (or both) are set up in the front of this section to generate a turbulent boundary layer. Finally, the air flows out from the diffuser with an increasing cross-section. The wind tunnel is controlled by a computer and the wind speed can be adjusted between 3 and $40 \mathrm{~m} \mathrm{~s}^{-1}$.

The configuration of the wind-tunnel experiment is as shown in Fig. 4. A 6-meter long roughness-element section is located in the front of the working section to generate a deep turbulent boundary layer. Downstream of this section is the test surface. A dust feeder is placed at the beginning of the working section to inject dust into the tunnel through a tubular manifold which consists of two rows of three outlets with even spacing of $0.2 \mathrm{~m}$ (Fig. 4a). The manifold is adjusted such that the bottom and the top rows are at approximately $0.2 \mathrm{~m}$ and $0.4 \mathrm{~m}$ above the top of the surface. After release, the dust particles are fully dispersed in the turbulent boundary layer over the test surface. The PDA is located near the end of the working section and the distance between the measuring point and the dust outlets is about $10 \mathrm{~m}$ to ensure sufficient development of the turbulent boundary layer and dust dispersion. The height of the measuring point is fixed with distance about $20 \mathrm{~mm}$ away from the top of the surface (Fig. 4c).

The PDA works best for spherical particles. Therefore, the optical characteristics and spherical degree of the particles are important factors which affect the reliability of the PDA measurements. A white powder of fused silica $\left(\mathrm{SiO}_{2}\right)$ with density of $2200 \mathrm{~kg} \mathrm{~m}^{-3}$ is selected as the dust source for our experiments. These particles have a good spherical degree and the mean diameter is $10 \mu \mathrm{m}$ (Fig. 5).

Dust deposition over different surfaces is investigated in our wind-tunnel experiments, including a wood surface (oiled by lubricating oil) and a water surface, which we will discuss later in detail. For both surfaces, the possibility of particle rebound should be low, and thus it is reasonable to assume that dust concentration at the surface is zero, an important assumption made in most dust deposition schemes. For these reasons, dust deposition over the wood and water surfaces is relatively simple and suitable for testing the PDA technique against theory and for examining the essence of dust deposition parameterizations. The experiments are then operated over sand, sandy loam, gobi (a surface consists of sands and gravels) and tree surfaces to produce a more complete data set.

The experimental procedure is as follows:

1. Preparation: the instruments are arranged as shown in Fig. 4. The sand and sandy loam surfaces are wetted and then air dried to produce a crust to prevent emission of surface particles.

2. Profile measurement: about 10 points of different heights are selected. Dust particles are released from the dust feeder and the speeds of dust particles passing through these points are measured by PDA. As the particles are small, their horizontal velocities can be considered to be the same as the local wind speed. The horizontal particle velocities and concentrations are measured one by one with duration of $3 \mathrm{~min}$, to produce mean wind and dust concentration profiles. Simultaneously, a device is fixed at a certain height to measure dust concentration with the purposes of monitoring stability of dust feeding and verifying reproducibility of the concentrations. 


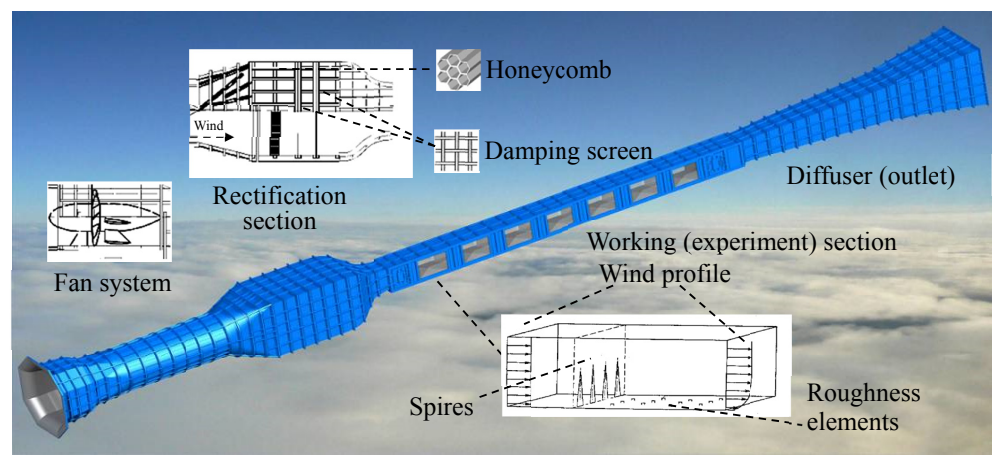

Figure 3. A sketch of the Lanzhou University wind tunnel.

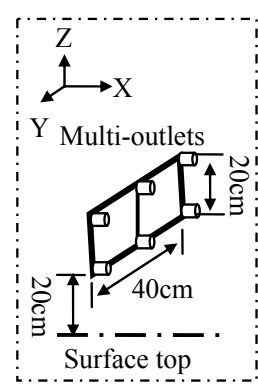

(a)

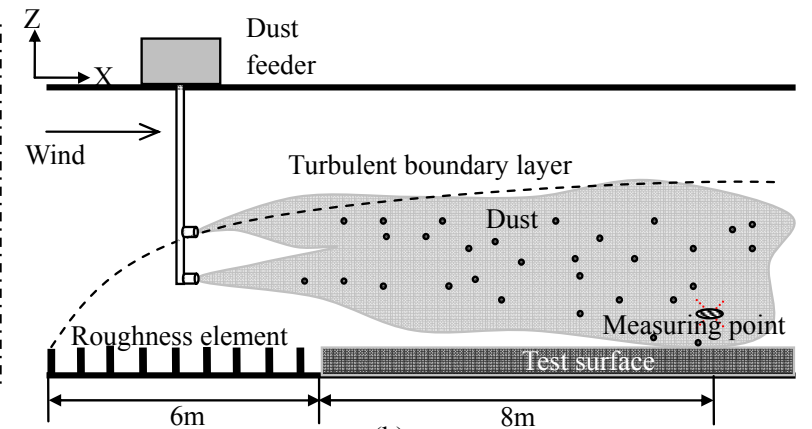

(b)

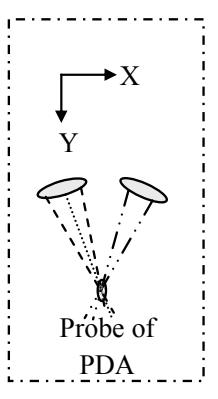

(c)

Figure 4. Configuration of the wind-tunnel experiment. (a) Dust feeding outlets; (b) Working section; the roughness elements fixed at the front of the working section generate a deep (at least $0.4 \mathrm{~m}$ ) turbulent boundary layer. Downstream of the roughness-element section is the test surface. A dust feeder is placed at the beginning of the working section and injects dust $\left(\mathrm{SiO}_{2}\right)$ into the tunnel through a tubular manifold. The measuring point is located near the end of the working section; (c) Probe of the PDA with laser beams intersecting at the measuring point.

3. Point measurement: a point, at about $20 \mathrm{~mm}$ above the top of surface, is selected for dust deposition measurement. The velocities and sizes of the particles that pass through this point are measured by PDA. The duration of the measurement is $10 \mathrm{~min}$.

4. Repeat: the surface is re-prepared and the Steps 2 and 3 are repeated.

The experiments are carried out for different wind speeds and for each wind speed at least 3 successful runs are made. Because PDA can only identify particles larger than $0.5 \mu \mathrm{m}$ (limited by the wavelength of the laser beam), the raw data are divided into the following of particle size bins, $0.5-1.5 \mu \mathrm{m}, 1.5-3 \mu \mathrm{m}, 3-5 \mu \mathrm{m}, 5-10 \mu \mathrm{m}, 10-15 \mu \mathrm{m}$, 15-20 $\mu \mathrm{m}, 20-25 \mu \mathrm{m}, 25-30 \mu \mathrm{m}, 30-50 \mu \mathrm{m}, 50-80 \mu \mathrm{m}, 80$ $100 \mu \mathrm{m}, 100-150 \mu \mathrm{m}$, and 150-200 $\mu \mathrm{m}$. For each bin, the particles are considered to be mono-dispersed with the respective median sizes of $1,2.25,4,7.5,12.5,17.5,22.5,27.5$, $40,65,90,125$, and $175 \mu \mathrm{m}$. The deposition velocity for each size bin is obtained by using the technique described in Sect. 3.

\section{Methodology of PDA data processing}

We now describe the method for deriving dust deposition velocity for different particle-size bins based on the PDA measurements. Our discussion is confined to the vertical direction. As shown in Fig. 6, the sampling area of PDA has a volume of $V$. If no particle appears in $V$, then dust concentration in the sampling area is zero. If particle $i$ of mass $m_{i}$ passes through $V$ with (vertical) velocity $w_{\text {pi }}$ then the corresponding concentration over the transit time $\Delta t_{i}$ is $m_{i} / V$ and the associated vertical dust flux is

$F_{\mathrm{di}}=\frac{m_{i}}{V} \cdot w_{\mathrm{pi}}$.

Suppose the sampling time interval is $T$, during which $N$ particles pass through $V$. Then, the average dust concentration $c$ and dust flux $F_{\mathrm{d}}$ are, respectively,

$$
\begin{aligned}
& c=\sum_{i=1}^{N}\left(\frac{m_{i}}{V} \cdot \frac{\Delta t_{i}}{T}\right) \\
& F_{\mathrm{d}}=\sum_{i=1}^{N}\left(\frac{m_{i}}{V} \cdot w_{\mathrm{pi}} \cdot \frac{\Delta t_{i}}{T}\right) .
\end{aligned}
$$




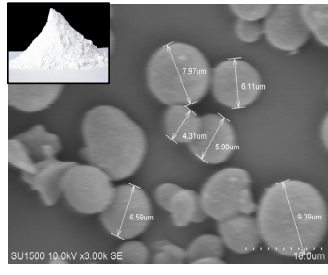

(a)

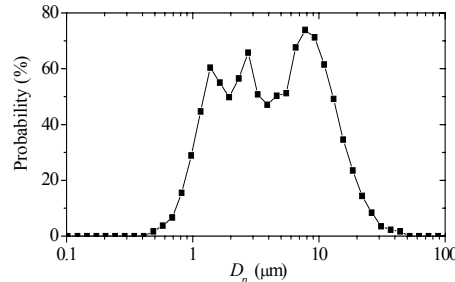

(b)
Figure 5. $\mathrm{SiO}_{2}$ powder used as dust for the wind-tunnel experiment. (a) Powder appearance (top left corner) and microscopic picture (measured by Scanning Electron Microscope, SU1500); (b) Probability distribution of particle size (measured by Particle Size Analyzer, S3500).

The deposition velocity can be expressed by combining Eqs. (2) and (3) as

$w_{\mathrm{d}}=\frac{\sum_{i=1}^{N}\left(D_{\mathrm{pi}}^{3} \cdot w_{\mathrm{pi}} \cdot \Delta \mathrm{t}_{i}\right)}{\sum_{i=1}^{N}\left(D_{\mathrm{pi}}^{3} \cdot \Delta \mathrm{t}_{i}\right)}$,

where $D_{\text {pi }}$ (particle diameter), $w_{\text {pi }}$ and $\Delta t_{i}$ are measured simultaneously by PDA.

The deposition velocity calculated with Eq. (4) includes the contributions of Brownian diffusion, eddy diffusion, gravitational settling and is possibly affected by the mean vertical wind $\bar{w}_{\mathrm{a}}$ which is generally considered to be zero under the condition of neutral boundary layer. But in our windtunnel experiments, it may be locally of the order of magnitude comparable to the particle terminal velocity. Even if it is zero in reality, error in flow measurements may still occur because a small alignment error in the PDA vertical with respect to the surface normal may result in interpreting a component of the horizontal wind as the vertical wind and cause a serious bias in the deposition velocity estimates. Therefore, we must remove the effect of $\bar{w}_{\mathrm{a}}$ from Eq. (4).

Our approach is to first remove the mean particle (vertical) motion $\left(\bar{w}_{\mathrm{p}}\right)$ from $w_{\mathrm{d}}$, which is composed of the mean air (vertical) motion $\left(\bar{w}_{\mathrm{a}}\right)$ and gravitational settling terminal velocity $w_{\mathrm{t}}$ (i.e. $\bar{w}_{\mathrm{p}}=\bar{w}_{\mathrm{a}}+w_{\mathrm{t}}$ ), then to add $w_{\mathrm{t}}$ back to $w_{\mathrm{d}}$. Equation (4) can now be written as

$w_{\mathrm{d}}=\frac{\sum_{i=1}^{N}\left(D_{\mathrm{pi}}^{3} \cdot w_{\mathrm{pi}} \cdot \Delta \mathrm{t}_{i}\right)}{\sum_{i=1}^{N}\left(D_{\mathrm{pi}}^{3} \cdot \Delta \mathrm{t}_{i}\right)}-\bar{w}_{\mathrm{p}}+w_{\mathrm{t}}$,

where $w_{\mathrm{t}}$ is computed with

$w_{\mathrm{t}}=\frac{C_{\mathrm{c}} \rho_{\mathrm{p}} D_{\mathrm{p}}^{2}}{18 \mu} \cdot g$,

with $C_{\mathrm{c}}$ being the Cunningham correction factor, $D_{\mathrm{p}}$ the mean particle diameter of the particle-size bin, $\mu$ dynamic (a)

(b)

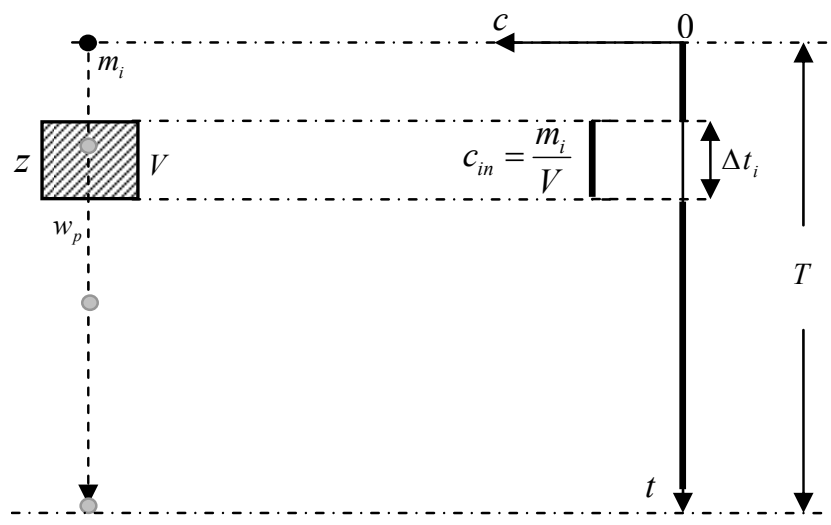

Figure 6. Illustration of one particle's contribution to dust concentration. (a) A dust particle (dot) passes through the sampling area (shaded); (b) Dust concentration corresponding to the situation shown in (a).

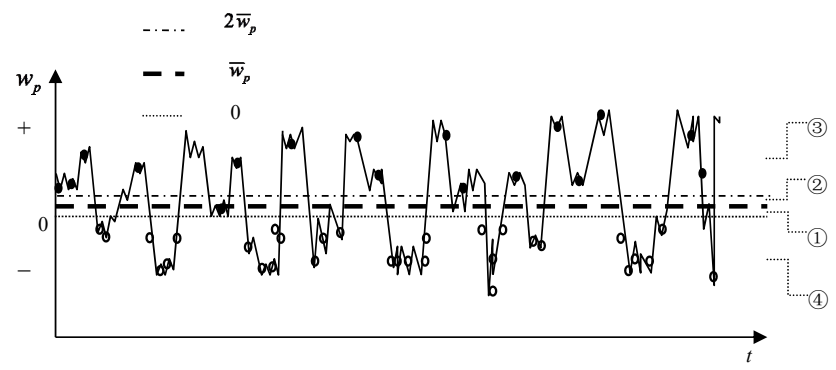

Figure 7. Illustration of the PDA data of particle velocity. Solid and open dots represent positive and negative $w_{\mathrm{p}}$ measured by PDA, respectively, and the solid line $w_{\mathrm{a}}+w_{\mathrm{t}}$. As an example, suppose $\bar{w}_{\mathrm{p}}>$ 0 , the full data set is divided into four parts: (1) $0<w_{\mathrm{p}}<\bar{w}_{\mathrm{p}}$; (2) $\bar{w}_{\mathrm{p}}<w_{\mathrm{p}}<2 \bar{w}_{\mathrm{p}} ;$ (3) $w_{\mathrm{p}}>2 \bar{w}_{\mathrm{p}}$; and (4) $\bar{w}_{\mathrm{p}}<0$.

air viscosity, $\rho_{\mathrm{p}}$ the particle density and $g$ the gravitational acceleration. However, the calculation of $\bar{w}_{\mathrm{p}}$ from the PDA particle-velocity measurements requires a correction of sampling bias. Particles observed by PDA can be considered to be discrete samplers of the flow speed. Due to the uneven particle-number distribution with height (e.g. more particles moving downward than upward), the sampling of $w_{\mathrm{p}}$ may be biased, as shown in Fig. 7. In that figure, the dots represent $w_{\mathrm{p}}$ measured by PDA, and the solid line $w_{\mathrm{a}}+w_{\mathrm{t}}$. The upward air motion is less frequently observed by PDA due to the lower dust concentration at lower height. The situation is the opposite for the downward air motion. To estimate $\bar{w}_{\mathrm{p}}$ (bold dashed line in Fig. 7), the full data set of $w_{\mathrm{p}}$ is initially divided into two subsets according to its sign, and $\bar{w}_{\mathrm{p}}$ is set to $\left(\bar{w}_{\mathrm{p}}^{+}+\bar{w}_{\mathrm{p}}^{-}\right) / 2$, with $\bar{w}_{\mathrm{p}}^{+}$and $\bar{w}_{\mathrm{p}}^{-}$being, respectively, the mean values of the positive and negative particle velocities. The full data set is then divided into four subsets as follows 

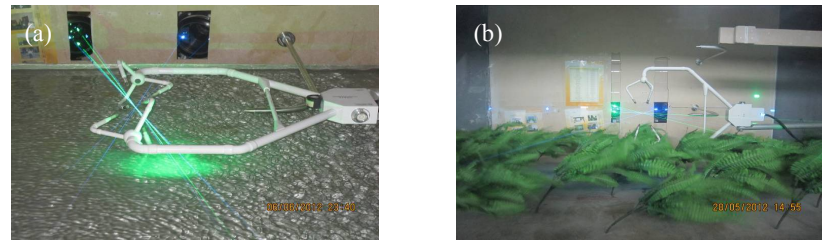

Figure 8. Examples of the test surfaces of (a) water, and (b) trees.

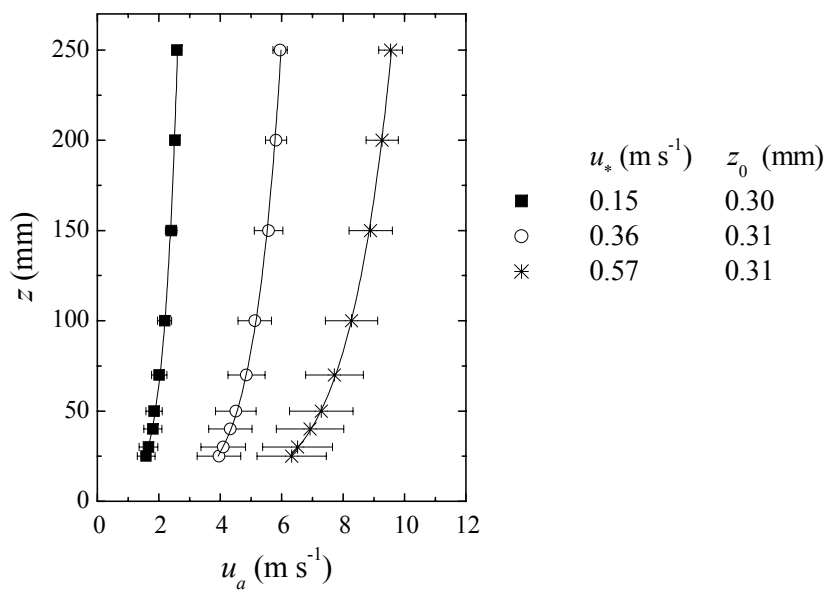

Figure 9. Wind profiles measured over the water surface for three experiments with the fan speed set to 3000,9000 and $12000 \mathrm{rpm}$. The dots are the mean wind speeds, and the error bars show the standard deviations. The curves are the logarithmic profiles fitted to the data.

1. $w_{\mathrm{p}} \in\left(0, \bar{w}_{\mathrm{p}}\right)$

2. $w_{\mathrm{p}} \in\left(\bar{w}_{\mathrm{p}}, 2 \bar{w}_{\mathrm{p}}\right)$

3. $w_{\mathrm{p}}>2 \bar{w}_{\mathrm{p}}$, if $\bar{w}_{\mathrm{p}}>0$ (or $w_{\mathrm{p}}<2 \bar{w}_{\mathrm{p}}$, if $\left.\bar{w}_{\mathrm{p}}<0\right)$; and

4. $w_{\mathrm{p}}<0$, if $\bar{w}_{\mathrm{p}}>0$ (or $w_{\mathrm{p}}>0$, if $\left.\bar{w}_{\mathrm{p}}<0\right)$.

The number of measurements of the subsets $j$ and $N_{j}$ are counted, and the average of particle velocity deviation of the

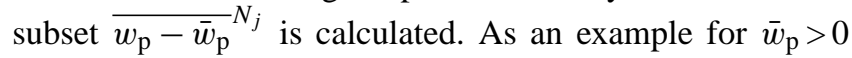
(corresponding to Fig. 7), $\bar{w}_{\mathrm{p}}$ is determined iteratively to satisfy

${\overline{w_{\mathrm{p}}-\bar{w}_{\mathrm{p}}}}^{N_{2}} \cdot \frac{N_{2}}{N_{2}+N_{3}}+{\overline{w_{\mathrm{p}}-\bar{w}_{\mathrm{p}}}}^{N_{3}} \cdot \frac{N_{3}}{N_{2}+N_{3}}=$

${\overline{w_{\mathrm{p}}-\bar{w}_{\mathrm{p}}}}^{N_{1}} \cdot \frac{N_{2}}{N_{2}+N_{3}}+{\overline{w_{\mathrm{p}}-\bar{w}_{\mathrm{p}}}}^{N_{4}} \cdot \frac{N_{3}}{N_{2}+N_{3}}$.

\section{Results}

Figure 8 shows two examples of the six surfaces tested in the experiments. For each surface, the experiment is repeated under three wind conditions. As an example, the wind profiles

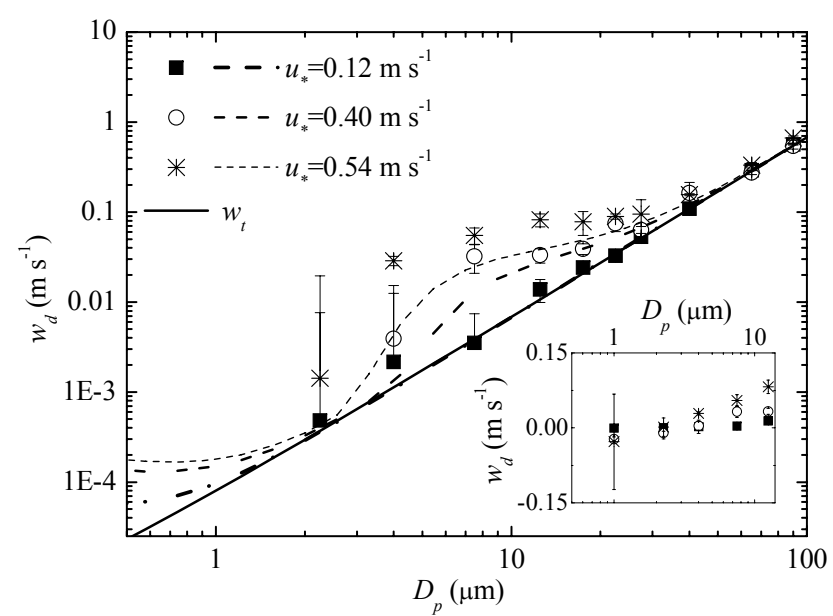

Figure 10. Deposition velocity against particle size under different wind conditions over the wood surface. The dots are averaged $w_{\mathrm{d}}$ and the error bars represent the variability of the three runs. The curves are the results predicted with the SS80 scheme. The height of the measuring point is $15 \mathrm{~mm}$ above the wood surface. $w_{\mathrm{d}}$ for small particles $(1-12.5 \mu \mathrm{m})$ have been inserted in the lower right corner to display the possible negative deposition velocities which impossibly appear in logarithmic coordinate system.

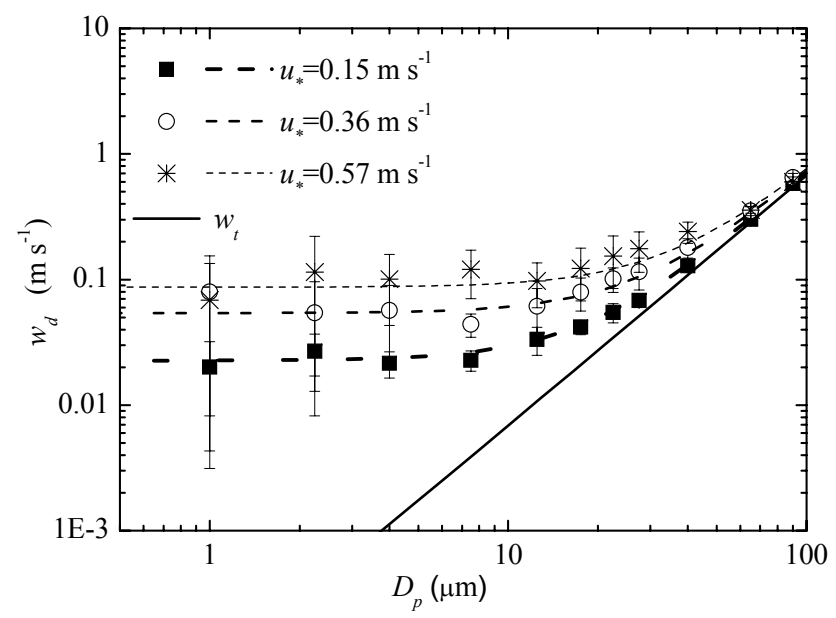

Figure 11. As Fig. 10, but for the water surface. The curves are the results predicted with the SS80 scheme by setting the laminar layer resistance $1 / w_{\mathrm{D}}$ to zero. The height of the measuring point is $25 \mathrm{~mm}$ above the water surface.

over the water surface are shown in Fig. 9. The logarithmical wind profile

$u_{\mathrm{a}}(z)=\left(u_{*} / \kappa\right) \cdot \ln \left[\left(z-z_{\mathrm{d}}\right) / z_{0}\right]$,

is fitted to the data for the estimates of friction velocity, $u_{*}$, and roughness length, $z_{0}$. The zero-plane displacement height, $z_{\mathrm{d}}$, is set to zero for the low-roughness surfaces (wood, water, sand, loam and gobi), but to $200 \mathrm{~mm}$ for the tree surface (the height of the trees is about $230 \mathrm{~mm}$ ). $\kappa$ is von Karman constant $(\sim 0.4)$. 

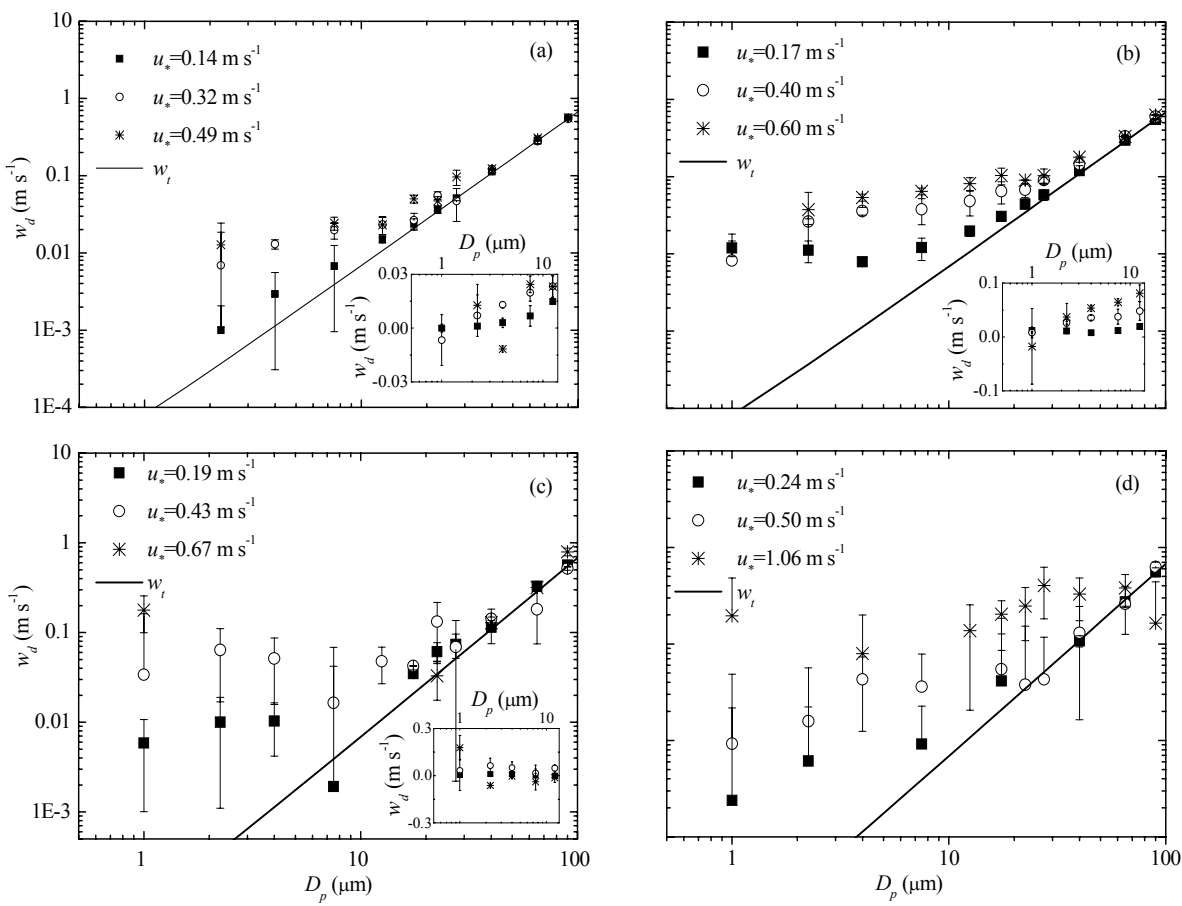

Figure 12. As Fig. 10, but for (a) sand, (b) sandy loam, (c) gobi, and (d) tree surface. For the tree surface, the measurement height is $z_{\mathrm{m}}=250 \mathrm{~mm}$.

Figure 10 shows the observed deposition velocity for the wood surface, which increases as expected with friction velocity. The SS80 scheme (Appendix A) is originally proposed for water surfaces, but is applicable to other smooth surfaces if the particle-growth mechanism embedded in the scheme is excluded. The predictions of the SS80 scheme are also shown in Fig. 10, which are generally comparable with the measurements although somewhat smaller. The underestimation by the scheme can be attributed to the inaccurate estimates of the dust transfer through the laminar layer. For very small particles (about $1 \mu \mathrm{m}$ ) under high friction velocity, the observed $w_{\mathrm{d}}$ showed occasional negative values (lower right corner of Fig. 10), probably due to the re-suspension of the deposited particles.

Water surface is special because it is wet and sticky. The air layer of high humidity adjacent to the water surface promotes the growth of hygroscopic particles and thereby enhances their gravitational settling. The SS80 scheme was proposed for parameterizing dust deposition to water surfaces by accounting for this mechanism. However, the dust particles used in our study are hydrophobic and thus the enhanced gravitational settling due to particle-size growth must be excluded from the SS80 scheme. Compared with the observation, the SS80 scheme is found to substantially underestimate dust deposition velocity (as shown in Fig. A2). The failure of the SS80 scheme is most probably due to the neglect of another important mechanism, that is, under windy conditions, dust deposition to the water surface can be significantly en- hanced by waves and spray droplets. The effects of waves and spray droplets are not included in the SS80 scheme, but can be accounted for by reducing the laminar layer resistance to zero. The predicted dust deposition velocities using the modified SS80 scheme by setting the laminar-layer resistance to zero are now found to agree much better with the measurements as shown in Fig. 11. It is also observed that $w_{\mathrm{d}}$ increases with friction velocity, and for particles in the size range of $1 \mu \mathrm{m}<D_{\mathrm{p}}<10 \mu \mathrm{m}, w_{\mathrm{p}}$ is almost constant (particlesize independent) for given wind speed. This is caused by the indistinctive collection of particles with different sizes by waves and spray droplets.

The above described techniques of wind-tunnel experiment and data analysis are also applied to sand, sandy loam, gobi, and tree surfaces. A relatively comprehensive data set of dust deposition for different surfaces, particle sizes and wind conditions is obtained, as shown in Fig. 12. Some negative deposition velocities were occasionally observed, possibly due to the additional dust emission from the surface. Although we took measures to reduce dust re-suspension and unwanted dust emission by oiling the surface or promoting crust formation prior to the experiment, it was not possible to entirely suppress the re-suspension of the dust deposited to the surface and dust emission from the surfaces when crust was destructed by wind and turbulence during the experiments. Also over the tree surface, occasional negative deposition velocities were observed. This may be caused by measurement errors in case of low dust concentrations for some 
particle-size bins, which result in inaccurate estimates of $\bar{w}_{\mathrm{p}}$ and hence $w_{\mathrm{d}}$.

The sand, sandy-loam, gobi, and tree surfaces are relatively rough surfaces. We have tested the existing dust deposition schemes against our data, but good agreements between the model predictions and the measurements cannot be achieved by setting the scheme parameters in reasonable ranges. A new scheme needs to be developed to overcome the deficiencies of existing schemes in parameterizing dust deposition over rough surfaces, which we will discuss in detail in a companion paper (Zhang and Shao, 2014).

It is appropriate to put our data set in perspective to the existing data published in the literature. However, dust deposition velocity is dependent on the reference height, $z_{\mathrm{r}}$, at which dust concentration is also measured to compute dust deposition flux. The measurement heights for existing experiments, including our work, are normally different. The same reference height is required to achieve a proper comparison. By considering the similar aerodynamic characteristic over different surfaces (logarithmic wind profile), the term of "same reference height" is defined as the same distance away from the zero-plane displacement height (here, we take $z_{\mathrm{r}}-z_{\mathrm{d}}=1 \mathrm{~m}$ ). To facilitate comparison, we have therefore corrected all data to this same reference height by solving dust concentration equation under the assumptions of steady and horizontal homogenous

$K_{\mathrm{p}} \cdot \frac{\partial c}{\partial z}+w_{\mathrm{t}} \cdot c=-F_{\mathrm{d}}=w_{\mathrm{d}} \cdot c$.

Here, the dust diffusivity $K_{\mathrm{p}}$ is set to $\kappa u_{*}\left(z-z_{\mathrm{d}}\right)$ and the dust deposition flux $F_{\mathrm{d}}$ is considered as a constant.

Then we have

$w_{\mathrm{d}}\left(z_{\mathrm{r}}\right)=\left\{\left[\frac{1}{w_{\mathrm{d}}\left(z_{m}\right)}-\frac{1}{w_{\mathrm{t}}}\right]\left(\frac{z_{m}-z_{\mathrm{d}}}{z_{\mathrm{r}}-z_{\mathrm{d}}}\right)^{\frac{w_{\mathrm{t}}}{\kappa u_{*}}}+\frac{1}{w_{\mathrm{t}}}\right\}^{-1}$,

where $w_{\mathrm{d}}\left(z_{\mathrm{r}}\right)$ is the deposition velocity at $z_{\mathrm{r}}$ and $z_{m}$ height of the measuring point.

The corrected data of our and other experiments (as shown in Fig. 1) are illustrated in Fig. 13. The results of our data show that the deposition velocity for particle bigger than $1 \mu \mathrm{m}$ increases with particle size and friction velocity. The comparisons between the measurements of different surfaces show that the deposition process is enhanced over water surface (because of waves and spray droplets) and over tree surface (because of efficient surface collection).

Figure 13 also shows the comparison between our data with the existing results corresponding to Fig. 1. As seen, for low-roughness surfaces, our data are in general consistent with the existing studies. Likewise, our measurements are comparable with the field observations for high-roughness surface. But we also note that, the deposition velocities measured in field seem to be larger than our measurements, under the similar wind friction velocity. That is may be caused by the complex surface condition which is hard to simulate in laboratory.

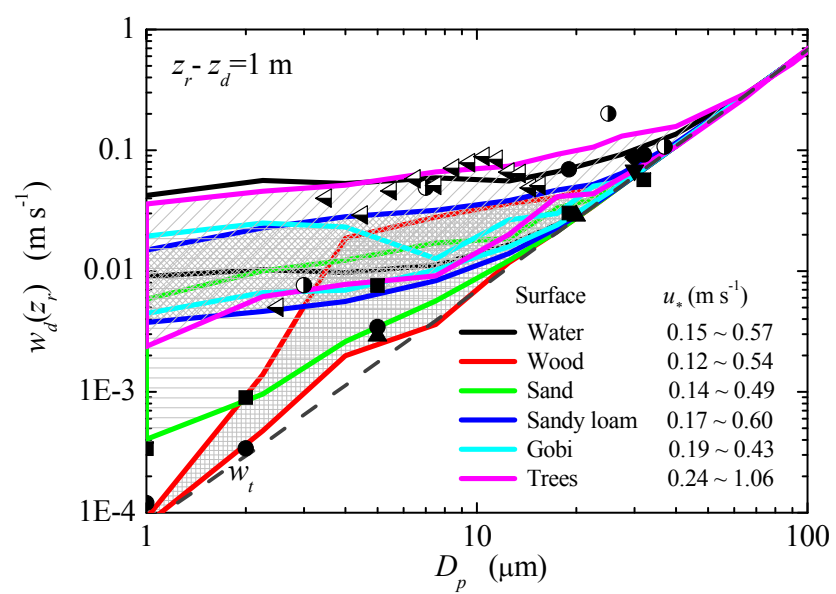

Figure 13. Comparison between the results of our measurements and other experiments. The lines and the shaded areas represent the range of dust deposition velocity over different surfaces, extracted from our data set. The dots are the results of the existing studies corresponding to Fig. 1 (with the same shape), but are recalculated to $z_{\mathrm{r}}=\left(z_{\mathrm{d}}+1\right) \mathrm{m}$.

\section{Summary}

We carried out a wind-tunnel experiment to measure dust deposition velocity for different particle sizes, surfaces and wind velocities. A new method based on the PDA technique was proposed for the measurements. This technique is more reliable than other dust deposition measuring techniques, as it directly measures the motion of the dust particles. The PDA method was first applied to a sticky-smooth wood surface and a water surface and the measurements compared with the SS80 scheme predictions. For these surfaces, the SS80 scheme is expected to work reasonably well. For the wood surface, good agreement between the measurements and the scheme predictions was found, and for the water surface, the measurements and the scheme estimates only agree if the effect of waves and spray droplets on dust deposition is taken into consideration. These comparisons confirm the effectiveness of the method we proposed.

After testing the PDA method for the simple (wood and water) surfaces, the technique was then applied to measuring dust deposition over four other surfaces including sand, sandy loam, gobi, and vegetated (tree) surfaces. A reliable data set of dust deposition velocity for six surface types, three velocities and 9 particle size groups (ranging from 1 to $40 \mu \mathrm{m}$ ) is obtained. This data set is an enrichment of the existing dust deposition data, has relatively high accuracy, and serves as a reference for development of dust deposition schemes.

It is found that dust deposition velocity for particles in the $1-40 \mu \mathrm{m}$ size range increases with particle size and friction velocity. In comparison with the other surfaces, the deposition velocity is large for the water surface (because of waves 
and spray droplets) and the tree surface (because of efficient surface collection). We have used the measurements to test the performance of some existing schemes and have found that they generally perform poorly for rough surfaces. This finding suggests that better representation of surface roughness elements in dust deposition schemes is required. In a companion paper, we will propose a new dust deposition scheme and validate the scheme with the observations from our wind-tunnel experiments. 


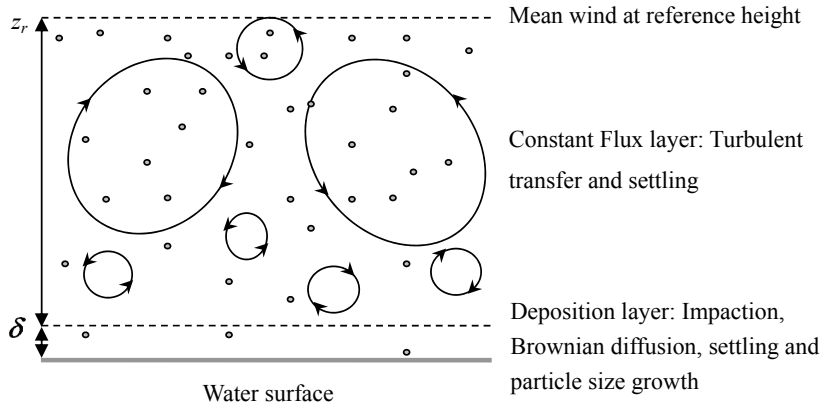

Figure A1. A schematic illustration of the two-layer model for dust deposition to a smooth surface.

\section{Appendix A: The Slinn and Slinn (1980) scheme for dust deposition}

Slinn and Slinn (1980) used a two-layer model (depicted in Fig. A1) to explain dust deposition over a water surface, which is considered to be smooth (without roughness elements) and wet (leading to hygroscopic growth of particle size). The atmosphere below a certain height is divided into two layers, an upper constant flux layer of depth $z_{\mathrm{r}}$, where turbulent diffusion dominates, and a lower deposition layer of depth $\delta$, where molecular diffusion dominates. Dust is transferred to the surface by impaction, Brownian diffusion and gravitational settling. The dust deposition velocity over the water surface is expressed as

$$
\frac{1}{w_{\mathrm{d}}}=\frac{1}{w_{C}}+\frac{1}{w_{D}}-\frac{w_{\mathrm{t}}\left(D_{\mathrm{p}}\right)}{w_{C} w_{D}},
$$

where

$w_{C}=\frac{1}{1-\kappa} \cdot \frac{u_{*}^{2}}{\bar{u}_{\mathrm{a}}\left(z_{\mathrm{r}}\right)}+w_{\mathrm{t}}\left(D_{\mathrm{p}}\right)$

is the transfer velocity for the upper layer, with $u_{*}$ being friction velocity, $\bar{u}_{\mathrm{a}}\left(z_{\mathrm{r}}\right)$ the mean wind speed at reference level $z_{\mathrm{r}}, \kappa$ the von Karman constant. $w_{\mathrm{t}}\left(D_{\mathrm{p}}\right)$ is the particle terminal velocity and

$w_{D}=-\alpha m^{\prime \prime}+\frac{1}{\kappa} \cdot \frac{u_{*}^{2}}{\bar{u}_{\mathrm{a}}\left(z_{\mathrm{r}}\right)} \cdot\left(S c^{-1 / 2}+10^{-3 / \tau_{\mathrm{p}}^{+}}\right)+w_{\mathrm{t}}\left(D_{p, w}\right)$

is the transfer velocity for the low deposition layer, where $m^{\prime \prime}$ represents the contribution from diffusiophoresis and $\alpha=$ $10^{3} \mathrm{~cm} \mathrm{~s}^{-1} /\left(1 \mathrm{~g} \mathrm{~cm}^{-2} \mathrm{~s}^{-1}\right)$. Hygroscopic growth of particles is taken into account. $D_{\mathrm{p}}$ and $D_{p, w}$ represent the diameter of dry and wet particle, respectively. Here, both the Schmidt number $(S c)$ and the dimensionless relaxation time $\left(\tau_{\mathrm{p}}^{+}\right)$relates to the wet particle diameter.

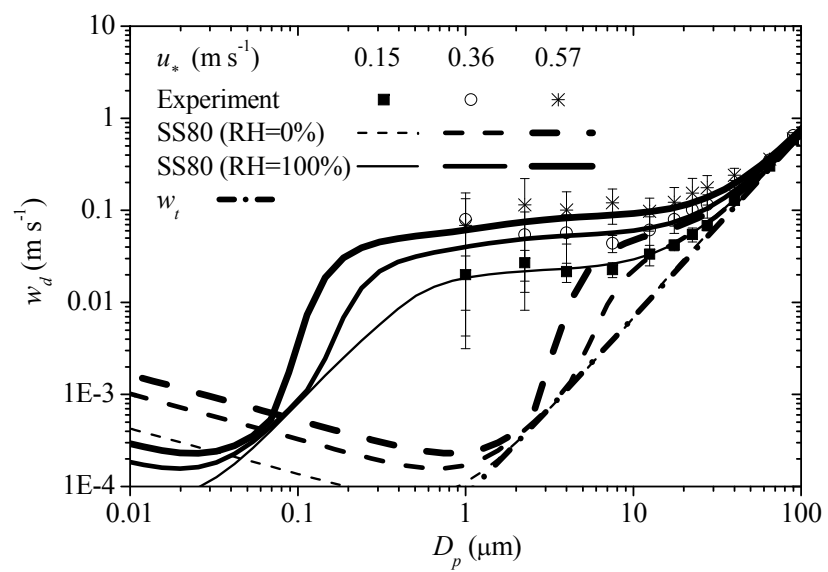

Figure A2. Results of our measurements and the SS80 scheme.

\section{A1 Comparison between our measurements and the results of the SS80 scheme}

We now compare the results of dust deposition velocity over water surface, between our measurement and the SS80 scheme. As shown in Fig. A2, the predicted results of the SS80 scheme under the condition of $\mathrm{RH}=100 \%$ (solid lines), which consider the particle growth effect, agree with the measurement (dots) well. But actually, the particles $\left(\mathrm{SiO}_{2}\right)$ used in our experiments do not satisfy the requirement of particle growth mechanism. This implies that the good agreement between the scheme and the measurements should be achieved by a wrong reason. In fact, we should set $\mathrm{RH}=0 \%$ to exclude the effect of particle growth. The predicted results of the SS80 scheme without the effect of particle growth is shown as the dash lines in Fig. A2. As seen, these predictions are substantially underestimated. We conclude that this failure of the SS80 scheme is caused by ignoring the effect of waves and bubbles or spray droplets emitted from the water surface. 
Appendix B: Data set of the wind-tunnel experiment

Table B1. List of wind-tunnel experiments.

\begin{tabular}{lllll}
\hline & \multicolumn{4}{c}{ Fan speed and repeat times } \\
\cline { 2 - 5 } Surfaces & $\begin{array}{l}3000 \mathrm{rpm} \\
\left(\sim 3 \mathrm{~m} \mathrm{~s}^{-1}\right)\end{array}$ & $\begin{array}{l}6000 \mathrm{rpm} \\
\left(\sim 5 \mathrm{~m} \mathrm{~s}^{-1}\right)\end{array}$ & $\begin{array}{l}9000 \mathrm{rpm} \\
\left(\sim 8 \mathrm{~m} \mathrm{~s}^{-1}\right)\end{array}$ & $\begin{array}{l}12000 \mathrm{rpm} \\
\left(\sim 11 \mathrm{~m} \mathrm{~s}^{-1}\right)\end{array}$ \\
\hline Water & 3 & 3 & 3 & $/$ \\
Sticky wood plane & 3 & - & 3 & 3 \\
Sand & 3 & 3 & 4 & - \\
Sandy loam & 3 & 3 & 3 & - \\
Gobi surface & 3 & 3 & 3 & - \\
Tree & 3 & 3 & - & 3 \\
\hline
\end{tabular}

Table B2. Dust deposition velocity for different particle sizes, wind speeds and surface conditions.

\begin{tabular}{|c|c|c|c|}
\hline \multirow{3}{*}{ Particle diameter $(\mu \mathrm{m})$} & \multicolumn{3}{|c|}{ Deposition velocity $\mathrm{w}_{\mathrm{d}}(z)\left(\mathrm{mm} \mathrm{s}^{-1}\right)$ on wood plane $\left(z_{\mathrm{m}}=15 \mathrm{~mm}, z_{\mathrm{d}}=0 \mathrm{~mm}\right)$} \\
\hline & $u_{*}\left(\mathrm{~m} \mathrm{~s}^{-1}\right) 0.12$ & 0.40 & 0.54 \\
\hline & $z_{0}(\mathrm{~mm}) 0.08$ & 0.03 & 0.03 \\
\hline 1 & $* 0.08 \pm-$ & $* 0.09 \pm-$ & $* 0.09 \pm-$ \\
\hline 2.25 & $0.48 \pm 7.16$ & $* 0.88 \pm-$ & * $1.42 \pm 18.21$ \\
\hline 4 & $2.16 \pm 13.15$ & $3.92 \pm 8.60$ & $28.78 \pm 3.42$ \\
\hline 7.5 & $3.52 \pm 3.89$ & $32.35 \pm 11.45$ & $55.02 \pm 11.46$ \\
\hline 12.5 & $13.86 \pm 3.96$ & $33.24 \pm 6.04$ & $82.12 \pm 13.65$ \\
\hline 17.5 & $24.13 \pm 2.11$ & $39.00 \pm 5.37$ & $78.20 \pm 22.99$ \\
\hline 22.5 & $32.79 \pm 2.01$ & $74.90 \pm 14.32$ & $89.66 \pm 6.20$ \\
\hline 27.5 & $53.35 \pm 0.30$ & $63.52 \pm 5.42$ & $94.86 \pm 42.90$ \\
\hline \multirow[t]{2}{*}{40} & $108.70 \pm 0.24$ & $163.72 \pm 49.74$ & $156.05 \pm 4.04$ \\
\hline & \multicolumn{3}{|c|}{ Deposition velocity $w_{\mathrm{d}}(z)\left(\mathrm{mm} \mathrm{s}^{-1}\right)$ on water surface $\left(z_{\mathrm{m}}=25 \mathrm{~mm}, z_{\mathrm{d}}=0 \mathrm{~mm}\right)$} \\
\hline \multirow[t]{2}{*}{ Particle diameter $(\mu \mathrm{m})$} & $u_{*}\left(\mathrm{~m} \mathrm{~s}^{-1}\right) 0.15$ & 0.37 & 0.57 \\
\hline & $z_{0}(\mathrm{~mm}) 0.30$ & 0.31 & 0.31 \\
\hline 1 & $20.07 \pm 11.85$ & $79.68 \pm 75.35$ & $68.65 \pm 65.51$ \\
\hline 2.25 & $26.90 \pm 9.86$ & $54.45 \pm 41.55$ & $114.86 \pm 106.63$ \\
\hline 4 & $21.57 \pm 5.1$ & $56.79 \pm 33.14$ & $101.05 \pm 58.07$ \\
\hline 7.5 & $22.79 \pm 4.21$ & $44.00 \pm 9.24$ & $120.70 \pm 50.24$ \\
\hline 12.5 & $33.36 \pm 8.37$ & $61.32 \pm 23.54$ & $97.50 \pm 37.93$ \\
\hline 17.5 & $41.87 \pm 5.47$ & $79.59 \pm 23.38$ & $122.56 \pm 55.14$ \\
\hline 22.5 & $54.77 \pm 9.44$ & $101.36 \pm 22.5$ & $153.46 \pm 68.54$ \\
\hline 27.5 & $68.17 \pm 8.35$ & $115.21 \pm 32.65$ & $176.56 \pm 62.62$ \\
\hline 40 & $128.48 \pm 6.80$ & $179.70 \pm 31.94$ & $240.83 \pm 46.5$ \\
\hline \multirow{3}{*}{ Particle diameter $(\mu \mathrm{m})$} & \multicolumn{3}{|c|}{ Deposition velocity $w_{\mathrm{d}}(z)\left(\mathrm{mm} \mathrm{s}^{-1}\right)$ on sand surface $\left(z_{\mathrm{m}}=15 \mathrm{~mm}, z_{\mathrm{d}}=0 \mathrm{~mm}\right)$} \\
\hline & $u_{*}\left(\mathrm{~m} \mathrm{~s}^{-1}\right) 0.14$ & 0.32 & 0.49 \\
\hline & $z_{0}(\mathrm{~mm}) 0.15$ & 0.14 & 0.13 \\
\hline 1 & $* 0.41 \pm-$ & $* 0.54 \pm-$ & $* 6.69 \pm-$ \\
\hline 2.25 & $1.00 \pm 1.06$ & $6.92 \pm 11.64$ & $12.74 \pm 11.64$ \\
\hline 4 & $2.95 \pm 2.64$ & $12.99 \pm 1.76$ & $* 16.2127$ \\
\hline 7.5 & $6.72 \pm 5.76$ & $19.71 \pm 4.65$ & $24.37 \pm 4.65$ \\
\hline 12.5 & $14.79 \pm 1.22$ & $23.29 \pm 6$ & $23.07 \pm 6$ \\
\hline 17.5 & $23.65 \pm 4.03$ & $26.51 \pm 6.01$ & $50.17 \pm 6.01$ \\
\hline 22.5 & $35.91 \pm 3.39$ & $55.56 \pm 6.42$ & $47.21 \pm 6.42$ \\
\hline 27.5 & $51.33 \pm 3.88$ & $47.01 \pm 21.35$ & $96.34 \pm 21.35$ \\
\hline 40 & $113.69 \pm 4.3$ & $121.97 \pm 1.76$ & $123.48 \pm 1.76$ \\
\hline
\end{tabular}


Table B2. Continued.

\begin{tabular}{|c|c|c|c|}
\hline \multirow{3}{*}{ Particle diameter $(\mu \mathrm{m})$} & \multicolumn{3}{|c|}{ Deposition velocity $\mathrm{w}_{\mathrm{d}}(\mathrm{z})\left(\mathrm{mm} \mathrm{s}^{-1}\right)$ on sandy loam surface $\left(z_{\mathrm{m}}=15 \mathrm{~mm}, z_{\mathrm{d}}=0 \mathrm{~mm}\right)$} \\
\hline & $u_{*}\left(\mathrm{~m} \mathrm{~s}^{-1}\right) 0.17$ & 0.40 & 0.60 \\
\hline & $z_{0}(\mathrm{~mm}) 0.85$ & 0.84 & 0.68 \\
\hline 1 & $* 4.86 \pm-$ & $8.21 \pm 9.85$ & $* 20.12 \pm-$ \\
\hline 2.25 & $* 6.32 \pm-$ & $26.24 \pm 2.35$ & $37.34 \pm 24.88$ \\
\hline 4 & $7.89 \pm 0.97$ & $35.71 \pm 4.13$ & $53.61 \pm 5.47$ \\
\hline 7.5 & $12.05 \pm 3.87$ & $37.64 \pm 13.89$ & $64.41 \pm 6.5$ \\
\hline 12.5 & $19.72 \pm 2.93$ & $48.20 \pm 17.19$ & $81.11 \pm 15.57$ \\
\hline 17.5 & $30.34 \pm 2.28$ & $64.89 \pm 20.73$ & $103.56 \pm 25.54$ \\
\hline 22.5 & $43.94 \pm 4.36$ & $67.40 \pm 14.14$ & $90.32 \pm 0.03$ \\
\hline 27.5 & $57.92 \pm 8.90$ & $90.44 \pm 8.21$ & $102.61 \pm 22.95$ \\
\hline \multirow[t]{2}{*}{40} & $119.43 \pm 0.94$ & $145.73 \pm 7.76$ & $178.70 \pm 5.40$ \\
\hline & \multicolumn{3}{|c|}{ Deposition velocity $w_{\mathrm{d}}(z)\left(\mathrm{mm} \mathrm{s}^{-1}\right)$ on gobi surface $\left(z_{\mathrm{m}}=15 \mathrm{~mm}, z_{\mathrm{d}}=0 \mathrm{~mm}\right)$} \\
\hline \multirow[t]{2}{*}{ Particle diameter $(\mu \mathrm{m})$} & $u_{*}\left(\mathrm{~m} \mathrm{~s}^{-1}\right) 0.19$ & 0.43 & 0.67 \\
\hline & $z_{0}(\mathrm{~mm}) 1.58$ & 1.09 & 1.05 \\
\hline 1 & $5.86 \pm 4.86$ & $* 37.28 \pm-$ & - \\
\hline 2.25 & $10.01 \pm 8.91$ & $63.72 \pm 46.8$ & - \\
\hline 4 & $10.31 \pm 6.14$ & $51.48 \pm 35.72$ & - \\
\hline 7.5 & $* 16.40 \pm-$ & $16.46 \pm 51.58$ & - \\
\hline 12.5 & $* 25.62 \pm-$ & $47.73 \pm 20.9$ & - \\
\hline 17.5 & $34.79 \pm 3.39$ & $42.39 \pm 0.32$ & - \\
\hline 22.5 & $61.10 \pm 16.08$ & $132.03 \pm 84.78$ & - \\
\hline 27.5 & $73.61 \pm 21.95$ & $69.00 \pm 66.8$ & - \\
\hline 40 & $114.19 \pm 1.91$ & $142.40 \pm 6.35$ & - \\
\hline \multirow{3}{*}{ Particle diameter $(\mu \mathrm{m})$} & \multicolumn{3}{|c|}{ Deposition velocity $\mathrm{w}_{d}(\mathrm{z})\left(\mathrm{mm} \mathrm{s}^{-1}\right)$ on tree surface $\left(z_{\mathrm{m}}=250 \mathrm{~mm}, z_{\mathrm{d}}=200 \mathrm{~mm}\right)$} \\
\hline & $u_{*}\left(\mathrm{~m} \mathrm{~s}^{-1}\right) 0.24$ & 0.50 & 1.06 \\
\hline & $z_{0}(\mathrm{~mm}) 5.93$ & 2.88 & 2.10 \\
\hline 1 & $2.38 \pm 19.27$ & $9.24 \pm 39.35$ & $* 48.04 \pm-$ \\
\hline 2.25 & $6.13 \pm 16.08$ & $15.79 \pm 40.74$ & $* 67.59 \pm-$ \\
\hline 4 & $* 7.76 \pm-$ & $42.96 \pm 30.58$ & $79.39 \pm 119.73$ \\
\hline 7.5 & $9.13 \pm 13.52$ & $36.03 \pm 42.69$ & $* 119.79 \pm-$ \\
\hline 12.5 & $* 20.14 \pm-$ & $* 35.28 \pm-$ & $137.55 \pm 116.91$ \\
\hline 17.5 & $41.25 \pm 44.56$ & $54.68 \pm 130.33$ & $203.97 \pm 76.49$ \\
\hline 22.5 & $* 43.71 \pm-$ & $37.81 \pm 114.76$ & $246.57 \pm 138.4$ \\
\hline 27.5 & $* 59.87 \pm-$ & $42.91 \pm 74.84$ & $403.57 \pm 221.76$ \\
\hline 40 & $107.28 \pm 14.26$ & $130.26 \pm 113.86$ & $328.59 \pm 154.32$ \\
\hline
\end{tabular}

* Estimated from the dust profile (polynomials) fitted to the experimental data. 
Acknowledgements. This work is supported by the DFG (Deutsche Forschungsgemeinschaft) project "A Wind-tunnel Study on Dust-deposition Mechanisms and Validation of Dust-deposition Schemes", the National Natural Science Foundation of China (Project 11172118) and the Innovative Research Groups of the National Natural Science Foundation of China (Project 11121202). We are grateful to Prof. Xiaojing Zheng for supporting this project and to the colleagues of Lanzhou University for providing assistance to carrying out the wind-tunnel experiments.

Edited by: A. Kiendler-Scharr

\section{References}

Alfaro, S. C. and Gomes, L.: Modeling mineral aerosol production by wind erosion: Emission intensities and aerosol size distributions in source areas, J. Geophys. Res., 106, 18075-18084, 2001.

Beswick, K. M., Hargreaves, K. J., Gallagher, M. W., Choularton, T. W., and Fowler, D.: Size-resolved measurements of cloud droplet deposition velocity to a forest canopy using an eddy correlation technique, Q. J. Roy. Meteor. Soc., 117, 623-645, 1991.

Bleyl, M.: Experimentelle Bestimmung der Depositionsgeschwindigkeit Luftgetragener Partikel mit Hilfe der EddyKovarianzmethode über einem Fichtenaltbestand im Solling, Ph.D. Thesis, Georg-August-Universität, Göttingen, 2001.

Chamberlain, A. C.: Transport of Lycopodium spores and other small particles to rough surfaces, Proc. Roy. Soc. Ldn., 296, 4570, 1967.

Clough, W. S.: Transport of particles to surfaces, J. Aerosol Sci., 4, 227-234, 1973.

Clough, W. S.: The deposition of particles on moss and grass surfaces, Atmos. Environ., 9, 1113-1119, 1975.

Dantec Dynamics A/S: BSA Flow Software Installation and User's Guide, Version 4.10, Skovlunde, 2006.

Gallagher, M. W., Beswick, K. M., Duyzer, J., Westrate, H., Choularton, T. W., and Hummelshøj, P.: Measurements of aerosol fluxes to speulder forest using a micrometeorological technique, Atmos. Environ., 31, 359-373, 1997.

Gallagher, W., Choularton, T., Morse, A., and Fowler, D.: Measurements of the size dependence of cloud droplet deposition at a hill site, Q. J. Roy. Meteorol. Soc., 114, 1291-1303, 1988.

Gao, Y., Arimoto, R., Duce, R. A., Zhang, X. Y., Zhang, G. Y., An, Z. S., Chen, L. Q., Zhou, M. Y., and Gu, D. Y.: Temporal and spatial distributions of dust and its deposition to the China Sea, Tellus 49B, 172-189, 1997.

Gillette, D. A.: Fine particulate emissions due to wind erosion, Trans. Am. Soc. Agricult. Eng., 20, 890-897, 1977.

Goossens, D. and Offer, Z. Y.: Wind tunnel and field calibration of six aeolian dust samplers, Atmos. Environ., 34, 1043-1057, 2000.

Goossens, D. and Rajot, J. L.: Techniques to measure the dry aeolian deposition of dust in arid and semi-arid landscapes: a comparative study in West Niger, Earth Surf. Proc. Land., 33, 178195, 2008.

Grönholm, T., Aalto, P. P., Hiltunen, V., Rannik, Ü., Rinne, J., Laakso, L., Hyvönen, S., Vesala, T., and Kulmala, M.: Measurements of aerosol particle dry deposition velocity using the relaxed eddy accumulation technique, Tellus B, 59, 381-386, 2007.
Hicks, B. B., Matt, D. R., McMillen, R. T., Womack, J. D., Wesely, M. L., Hart, R. L., Cook, D. R., Lindberg, S. E., de Pena, R. G., and Thomson, D. W.: A field investigation of sulfate fluxes to a deciduous forest, J. Geophys. Res., 94, 13003-13011, 1989.

Ishizuka, M., Mikami, M., Leys, J., Yamada, Y., Heidenreich, S., Shao, Y., and McTainsh, G. H.: Effects of soil moisture and dried raindroplet crust on saltation and dust emission, J. Geophys. Res., 113, D24212, doi:10.1029/2008JD009955, 2008.

Liu, L. Y., Shai, P. J., Gao, S. Y., Zou, X. Y., Erdon, H., Yan, P., Li, X. Y., Ta, W. Q., Wang, W. Q., and Zhang, C. L.: Dustfall in China's western loess plateau as influenced by dust storm and haze events, Atmos. Environ., 38, 1699-1703, 2004.

Marticorena, B. and Bergametti, G.: Modeling the atmospheric dust cycle: 1. Design of a soil-derived dust emission scheme, J. Geophys. Res., 100, 16415-16430, 1995.

Nemitz, E., Gallagher, M. W., Duyzer, J. H., and Fowler, D.: Micrometeorological measurements of particle deposition velocities to moorland vegetation, Q. J. Roy. Meteor. Soc., 128, 22812300, 2002.

Ould-Dada, Z.: Dry deposition profile of small particles within a model spruce canopy, Sci. Total Environ., 286, 83-96, 2002.

Pryor, S. C., Larsen, S. E., Sørensen, L. L., Barthelmie, R. J., Grönholm, T., Kulmala, M., Launiainen, S., Rannik, Ü. and Vesala, T.: Particle fluxes over forests: Analyses of flux methods and functional dependencies, J. Geophys. Res., 112, D07205, doi:10.1029/2006JD008066, 2007.

Pryor, S. C., Larsen, S. E., Sørensen, L. L., and Barthelmie, R. J.: Particle fluxes above forests: observations, methodological considerations and method comparisons, Environ. Pollut., 152, 667678, 2008.

Sehmel, G. A.: Particle diffusivities and deposition velocities over a horizontal smooth surface, J. Colloid Interf. Sci., 37, 891-906, 1971.

Seinfeld, J. H. and Pandis, S. N.: Atmospheric chemistry and physics: from air pollution to climate change, second edition, John Wiley \& Sons, Inc., Hoboken, 923-927, 2006.

Shao, Y.: A model for mineral dust emission, J. Geophys. Res., 106, 20239-20254, 2001.

Shao, Y:: Simplification of a dust emission scheme and comparison with data, J. Geophys. Res., 109, D10202, doi:10.1029/2003JD004372, 2004.

Shao, Y., McTainsh, G. H., Leys, J. F., and Raupach, M. R.: Efficiencies of sediment samplers for wind erosion measurement, Soil Res., 31, 519-532, 1993

Slinn, S. A. and Slinn, W. G. N.: Predictions for particle deposition on natural waters, Atmos. Environ., 14, 1013-1016, 1980.

Slinn, W. G. N.: Predictions for particle deposition to vegetative canopies, Atmos. Environ., 16, 1785-1794, 1982.

Sow, M., Goossens, D., and Rajot, J. L.: Calibration of the MDCO dust collector and of four versions of the inverted frisbee dust deposition sampler, Geomorphology, 82, 360-375, 2006.

Textor, C., Schulz, M., Guibert, S., Kinne, S., Balkanski, Y., Bauer, S., Berntsen, T., Berglen, T., Boucher, O., Chin, M., Dentener, F., Diehl, T., Easter, R., Feichter, H., Fillmore, D., Ghan, S., Ginoux, P., Gong, S., Grini, A., Hendricks, J., Horowitz, L., Huang, P., Isaksen, I., Iversen, I., Kloster, S., Koch, D., Kirkevåg, A., Kristjansson, J. E., Krol, M., Lauer, A., Lamarque, J. F., Liu, X., Montanaro, V., Myhre, G., Penner, J., Pitari, G., Reddy, S., Seland, Ø., Stier, P., Takemura, T., and Tie, X.: Analysis and quantifica- 
tion of the diversities of aerosol life cycles within AeroCom, Atmos. Chem. Phys., 6, 1777-1813, doi:10.5194/acp-6-1777-2006, 2006.

Textor, C., Schulz, M., Guibert, S., Kinne, S., Balkanski, Y., Bauer, S., Berntsen, T., Berglen, T., Boucher, O., Chin, M., Dentener, F., Diehl, T., Feichter, J., Fillmore, D., Ginoux, P., Gong, S., Grini, A., Hendricks, J., Horowitz, L., Huang, P., Isaksen, I. S. A., Iversen, T., Kloster, S., Koch, D., Kirkevåg, A., Kristjansson, J. E., Krol, M., Lauer, A., Lamarque, J. F., Liu, X., Montanaro, V., Myhre, G., Penner, J. E., Pitari, G., Reddy, M. S., Seland, Ø., Stier, P., Takemura, T., and Tie, X.: The effect of harmonized emissions on aerosol properties in global models an AeroCom experiment, Atmos. Chem. Phys., 7, 4489-4501, doi:10.5194/acp-7-4489-2007, 2007.
Uno, I., Wang, Z., Chiba, M., Chun, Y. S., Gong, S. L., Hara, Y., Jung, E., Lee, S. S., Liu, M., Mikami, M., Music, S., Nickovic, S., Satake, S., Shao, Y., Song, Z., Sugimoto, N., Tanaka, T., and Westphal, D. L.: Dust model intercomparison DMIP study over Asia: overview, J. Geophys. Res., 111, D12213, doi:10.1029/2005JD006575, 2006.

Wesely, M. L., Cook, D. R., and Hart, R. L.: Fluxes of gases and particles above a deciduous forest in wintertime, Bound.-Lay. Meteorol., 27, 237-255, 1983.

Wesely, M. L., Cook, D. R., Hart, R. L., and Speer, R. E.: Measurements and parameterization of particulate sulfur dry deposition over grass, J. Geophys. Res., 90, 2131-2143, 1985.

Zhang, J. and Shao, Y.: A new parameterization of dust dry deposition over rough surfaces, Atmos. Chem. Phys. Discuss., 14, 8063-8094, doi:10.5194/acpd-14-8063-2014, 2014. 